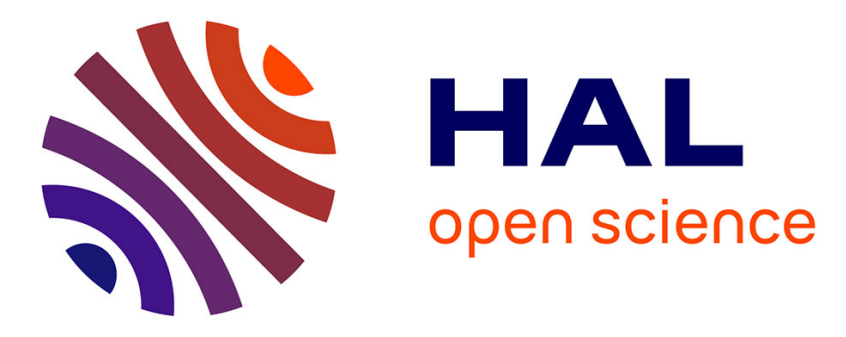

\title{
The Need for Knowledge Management When Backsourcing is Embraced
}

Bella B. Nujen, Rickard Damm

\section{To cite this version:}

Bella B. Nujen, Rickard Damm. The Need for Knowledge Management When Backsourcing is Embraced. IFIP International Conference on Advances in Production Management Systems (APMS), Sep 2016, Iguassu Falls, Brazil. pp.748-755, 10.1007/978-3-319-51133-7_88 . hal-01615805

\section{HAL Id: hal-01615805 \\ https://hal.inria.fr/hal-01615805}

Submitted on 12 Oct 2017

HAL is a multi-disciplinary open access archive for the deposit and dissemination of scientific research documents, whether they are published or not. The documents may come from teaching and research institutions in France or abroad, or from public or private research centers.
L'archive ouverte pluridisciplinaire HAL, est destinée au dépôt et à la diffusion de documents scientifiques de niveau recherche, publiés ou non, émanant des établissements d'enseignement et de recherche français ou étrangers, des laboratoires publics ou privés. 


\title{
The Need for Knowledge Management when Backsourcing is Embraced
}

\author{
Bella B. Nujen ${ }^{1}$ and Rickard Damm ${ }^{2}$ \\ 1 Molde University College, Molde, Norway \\ Bella.B.Nujen@himolde.no \\ 2 TeliaSonera, Sweden
}

\begin{abstract}
This paper focuses on a relatively new sourcing strategy referred to as backsourcing, where we emphasize the importance of knowledge reintegration and how it can be managed. Our reference for this approach is built upon Knowledge Management theory and contribution from different academics that have discussed and highlighted the reversal of global manufacturing strategies. This is illustrated through an interview study with three members within the maritime industry at a high-cost location, which have already embraced a backsourcing strategy, or are preparing to embark on one. Findings in this paper contribute toward providing strategic choices that should be considered when reintegrating globally fragmented knowledge.
\end{abstract}

Keywords: Knowledge Management - Manufacturing · Backsourcing · Backshoring

\section{Introduction}

The reversal of global outsourcing strategies through e.g. backsourcing or backshoring has led to the rethinking of core competence within businesses and has highlighted the importance of how to retain or revive knowledge platforms within manufacturing sectors [1]. Earlier, work within manufacturing was usually assumed to consist of simpler assembly work. However, much of the work conducted within manufacturing consists of complex work sequences which require hands-on knowledge which sometimes, because of its tacitness and contextual embeddedness, does not lend itself to be easily articulated or codified. Hence, according to knowledge- and innovation theories these types of dimensions and capabilities are of fundamental importance since they underpin the further development of extant and new knowledge which are crucial elements for innovation to occur $[2,3]$. According to [4] manufacturing strategies should not be restricted to, "... only cover quantifiable aspects such as how much-, how- and where- to produce. Stakeholder's relations, knowledge and innovativeness, and organiza-tional culture are examples of intangible aspects that are increasingly important in manufactur-ing strategies" (p.1) [4]. The current discussion indicates that businesses of today have to manage their work within manufacturing 
differently and apply it beyond traditional logistics measurements. Hence, manufacturing organizations are no longer limited to assembling and improvements, instead they consist of more intangible resources and capabilities that are both contextual and individual bounded. A wider exploration of how to manage these capabilities might therefore be necessary in today's competitive environment. Especially since there is a shift towards a more advanced manufacturing industry which not only incorporates new technology but also needs to revive important knowledge within an organizations own boundaries. Empirical research shows that important knowledge especially of the tacit dimension is about to erode within different industries like e.g. the US auto industry discussed by [5] and the Norwegian shipbuilding industry discussed by [1] and co-authors. In theoretical and empirical terms, there is a need to combine the interest in Knowledge Management $(\mathrm{KM})$ and development when re-evaluating capabilities in relation to a successful sourcing- and manufacturing strategy.

In this paper we focus on a relatively new sourcing strategy referred to as backsourcing, where we emphasize the importance of knowledge re-integration within manufacturing. Our reference for this approach is built upon KM theory and contribution from different academics that have discussed and highlighted the reversal of global sourcing strategies. This is illustrated through an interview study with three members within the maritime industry at a high-cost location which have already embraced a backsourcing strategy, or are preparing to embark on one. Data was collected through in-depth semi-structured individual interviews with seven leaders on strategic levels. All interviews, except for one, were conducted on site, recorded and later transcribed verbatim. Additional data was obtained from published company documents regarding their new choice of sourcing strategy.

The composition of the paper is as follows: First, we give a brief introduction to the field of reversed global sourcing strategies, concluding with the need of a greater use of KM principles. Chapter 2 highlights potential challenges which may come of re-transferring and re-integrating a once outsourced activity or competence. Chapter 3 gives a presentation of the case, which also represents the frame of reference for the discussion and conclusion in chapter 4 .

\section{Theoretical Background}

\subsection{The Reversal of Global Outsourcing Strategies}

Global outsourcing, also referred to as offshoring, is part of the disaggregation of the value chain, and represents a critical interface between assets and geography where organizations try to achieve a competitive edge, by combining comparative advantages, usually at different low-cost locations with in-house resources [6]. The leading arguments for the strategy is to understand which part of the operational setup that are not core, to enable other companies to create the organizational scale and leverage needed to run a specific production or service process. Thus, theory shows that cost considerations are highly emphasized in favor of core competence [7]. According to [8] and co-authors, we are 
now rethinking global outsourcing strategies, which has been the dominating choice of strategy within manufacturing for almost 50-years. Today, a growing attention is being paid to global contracting failures and increased labour costs at traditionally low-cost locations among manufacturing businesses, which has led to different choices of where and how to produce in addition to where to source from. Consequentially, organizations not only source in the direction from internal- to external environments, but also from external back to internal. The latter phenomenon can be seen as a trend of global outsourcing fade-out, or simply as a sign that outsourcing as part of a manufacturing strategy continues to be transformed adapted and developed in parallel with the inherent global environment.

Hence, as a consequence of the aforementioned issues, together with the increas-ingly knowledge intensive corporate climate, a new trend has emerged called backsourcing. Backsourcing can be defined as the process of recalling operations "back in-house" after they have been (globally) outsourced [9].

Others define it as the process of bringing once outsourced activities back into the organization, with the goal of rebuilding internal capabilities [10]. The latter definition of the phenomenon describes backsourcing as a strategy and includes a perception of rebuilding which is a significant aspect to consider when one decides whether to bring back an activity (including personnel) or not, which is the definition this paper supports. Thus, this is only one of several relocation strategies which have emerged during the last decade or so.

Others are referred to in similar terms such as backshoring, reshoring, homesourcing, inshoring and nearshoring $[7,9,11]$ which all include a recall of value creation processes back to the original manufacturing-location or to a neighboring country. What's interesting though is that these strategies have a greater emphasizes with regards to location aspects [8] compared to the overall backsourcing strategy, where the activity that is being brought back, is more dependent on the ownership structures. This important feature of the backsourcing definition is worth noting, since there seems to be a confusion regarding the more traditional definition when activates are being performed in-house, referred to as insourcing. Here, one is usually buying-in external resources to work under in-house management, where the activity that is being bought has not previously been developed or owned by the buyer [10] which is a significant difference from the backsourcing definition, but also from the above mentioned ones, since they all imply a re-integration of an activity or process, either back in-house, or relocated from a foreign location back to the home location or a neighboring one. Furthermore, the current discussion and academic field of reversed global outsourcing strategies, show that some of the circumstances fall under the heading of correcting prior (poor) decisions, whereas others fall under the course of responding to changes in the environment, technologies and competitiveness of the foreign and home location [7].

However, despite the aforementioned research, there is still a conspicuous absence as far as substantial elaboration, regarding the knowledge re-integration process, especially in relation to the management part of it. 


\subsection{Incorporating Knowledge Management}

Knowledge is a complex phenomenon with several different dimensions, where the most commonly referred is provided by [12] where he makes a distinction between a tacit and an explicit one. Tacit knowledge can be characterized as personal, abstract and difficult to communicate by verbal articulation, in contrast to explicit knowledge, which is codified knowledge, easy to communicate and transform since it in theory has a universal way of interpretation Furthermore, tacit knowledge is embedded in organizational structures through common knowledge platforms, culture, mind-sets and competences that are shared through interaction between members, which gives it a context specific dimension $[3,12,13]$.

When organizations are going global with their resources they are letting go of capabilities and skills, which involves transformation of embodied knowledge. After all, capabilities are to a large extent carried out, in one way or another, by the members of the organization using their individual competencies and skills involving the tacit knowledge dimension, which may cause potential problems of retention and accumulation within the organizational boundaries. As earlier mentioned, manufacturing work of today consists of more intangible resources and capabilities, which require hands-on tacit knowledge. Distinctive core capabilities, which usually are unique because of their tacitness, can be strengthened if the organization focuses on knowledge building [3,14]. However, to achieve this one needs to identify and nurture activities that are built upon extant knowledge. A change in the employee base and the related tacit knowledge might be lost as a result of outsourcing. Nevertheless, this does not mean that organizations are not acquiring knowledge at foreign location, they are, but global outsourcing disrupts and might hamper informal social networks, structures and processes that play a critical role in an organization's system of creating, integrating and sharing knowledge $[2,6]$.

Knowledge challenges will however often differ between strategies, which imply that the enablers for a successful knowledge transfer also may differ. A redefinition of the importance of specific knowledge, which is necessary within the organizational context, is therefore crucial [9]. Re-integration and the reviving of potentially lost competence might therefore be more easily facilitated through relocation, either in-house, nearby or to a more controlled structure.

Hence, even though it may look like it, we are not proposing that backsourcing is the best or right solution for all manufacturing organizations. However, when choosing to embark on one or another reversal form of global sourcing strategy, businesses need to incorporate a KM perspective, especially when a product or activity has been modified or changed dramatically at the outsourced organization. The success of re-integrating an outsourced activity will to a large extent depend on the presence of an in-house organizational knowledge platform [1] and the ability to capture and understand what types of knowledge that needs to be re-integrated, as well as making sure that the "right" knowledge dimension fits its organizational origin $[9,13,14]$. Nevertheless, outsourcing operations are challenging and costly to reverse. For example, if the contract has not ended, and the firm chooses to backsource because of e.g. quality, trust 
or lead-time dissatisfaction, one should carefully consider possible termination penalties, duties and responsibility agreements. Especially if the recall-activity involves confidential information or product protection, which might lead to expensive legal processes, in addition to hampering the chances of a successful knowledge-reintegration.

Consequentially, one of the most challenging obstacles when embarking on a backsourcing strategy relate to re-integrating or reviving knowledge. Organizations generally put too much focus on the aspects of knowledge itself, and neglect other important aspects such as the management part of it which is equally important when knowledge is transferred from one environment to another $[3,14]$.

\section{Three Members from the Maritime Industry}

This case is illustrated through in-depth interviews with three members $(\mathrm{A}, \mathrm{B}$, C) from the maritime industry at a high-cost location in Scandinavia, were we describe their decisions concerning their choice of knowledge-operations and activities, through a backsourcing process. Company A and B are both part of a unique offshore cluster, where $\mathrm{A}$ is the largest family-owned shipbuilding organization in its country, and delivers complex and specialized vessels to demanding ship owners worldwide. Company B is a sub-supplier offering large winches and fairleads, mainly to yards, ship-owners and oil companies. Company C, offers innovative products and processes for the offshore sector, as well as for marine, furniture and aquaculture industries. All of the companies announced that they embarked on outsourcing during the 1990s; which first and foremost where based on, cost consideration in production processes, but also because of an so called "herd mentality".

The consequences of outsourced activities for all three companies have been described as partial erosion of their core competencies, and to some extent also for the nation. "25 years ago we built in this country, however because of the search for cheaper manufacturing workers, we lost some of our competitiveness which forced us out of our regions..." and "... the steel competence is about to erode, which is not only a problem for the yards, but also for the entire value chain..." Company A and C have both carried out a backsourcing strategy, while $\mathrm{B}$ is actively preparing to embark on one. However the reasons behind the decision are different for each one of the firms.

For company A it was not a deliberate strategic decision that led to their backsourcing journey, instead it was a lead-time aspect which was important for enabling them to win a contract, behind their action. Nevertheless, over time it developed into a decision of significant strategic importance for how they choose to continue with their future manufacturing activities.

Instead of constructing complete hulls through a third-party, using traditional assembling processes, they brought back critical parts and started to modularize these through automation and robotics in-house, which resulted in operational advantages such as increased flexibility. However, it was the awareness around their in-house knowledge base and their access to their employee's tacit knowl- 
edge and important know-how, which led to a stronger desire to start with a wider backsourcing strategy. Thus, they also saw the need to develop new capabilities which led to hiring people with technology know-how and strategically encourage knowledge sharing within the organization through learning by doing and programmes supporting experience-based collective action with their existing workforce which was the same as the one before their outsourcing process.

The underlying message from these managers is that the company started to direct more attention to knowledge as a key strategic resource, since they saw that "...the re-integration process depended on it as well as our future competitiveness".

Similar to company A, C's decision to backsource also started as a coincidence. The company participated in an international innovation project where they developed and invested in a machine which at the time was considered a failure, accumulating a loss of about 25 MNOK (Million Norwegian Kronor). However, when an opportunity appeared in the market for molding of large parts, it turned out they had just the machine needed. Previously these parts where mostly molded with the help of simpler automation processes and manual work, however when it came to large parts it was extremely labour intensive. This experience made the company realize that competitors in the international market were not necessarily more competitive than themselves, leading towards a higher desire and understanding that they could produce these large products in-house because of the enabling technology being a differentiator in combination with their employees knowledge about it "... sometimes we have a tendency to worship international competitors for more than they are worth..." Nevertheless, what this event led to was a realization that if there existed high enough knowledge in-house, and the activity in question is demanding enough and at the same time the direct labour costs are low enough, then accordingly the possibility for automation is profitable, which enables production at high cost locations.

Hence, just like company A, C had almost the same workforce as before they outsourced. Today, they have carved out a profitable niche in this market and $30 \%$ of their turnover last year came as a result of backsourcing activities from China. It should be mentioned though that the organization always has been innovation and technology driven, likewise when it comes to knowledge development.

Company $\mathrm{C}$ has a systematic process of storing employees (explicit) knowledge in different IT systems compared to company A, which is more traditional when it comes to internal knowledge seeking and technology use. And moreover, when trying to develop and integrate tacit knowledge, company $\mathrm{C}$ has a policy that at least one engineer in every innovation- or research project is involved, which is a requirement for participation. "... if the person who develops the product does not possess production expertise, then he produces bad products or products that are difficult to produce, which in turn also makes it difficult to achieve good quality, which makes it challenging to commercialize"

In contrast to both A and C, company B has been working deliberately towards a backsourcing strategy for some years now. Learning from other organi- 
zations within their cluster as well as other industries at high cost locations, they have made heavy investments in technology. The technological approach perspective is what underpins their entire make or buy decisions today, and are analyzed on a scale described as, " technically too simple, too complex or technically proper". The goal is to backsource production activities and design processes, but only those that fit their available technology "... technology controls which activity we should produce in-house, not the production- or knowledge base..." Their strategy is that the company should always invest in the best compatible technology (maximum technology/feature) and not by optimal technology. Obtaining this reasoning and combining it with the economic situation, they have discovered that in-house production has more benefits than was predicted. What is interesting though is that all of their employees have steel/welding or machinery certifications (which is obligatorily), and not a technological education in e.g. Computer Science. Consequently, their organizational knowledge platform is primarily based on hands-on knowledge developed through social interaction and experience (tacit) which also is the basis of their historical development. Nevertheless it is technology that decides how to produce or where to source from, not their core common platform.

That being said, the company desires a new knowledge platform which incorporates a higher technological dimension, however, still demanding a steel/welding certification from their employees "... our knowledge platform is not always common, but in constant renewal". Nevertheless, they have not yet managed to bring back outsourced activities in-house. And top management still have a strong aspiration to continue preparing for implementing a backsourcing strategy through knowledge renewal, focusing on technological developments.

\section{Discussion and Conclusion}

This interview study illustrates that when embarking on reversed outsourcing strategies, organizations need to be capable of renewing capabilities to cover additional types of knowledge and reconfigure existing knowledge into new types of competencies. However, to be able to renew knowledge, you need to know what you know, and therefore also create an ability to revive previous knowledge. Implementing KM strategies when relocating recourses back to the organization's own boundaries is therefore of fundamental importance. Furthermore, the need to retain staff even after the organization has outsourced is a defining feature for knowledge accumulation, creating a strong organizational knowledge platform, which in turn can become an enabler for innovation and knowledge development.

This highlights the importance of identifying and addressing both tacit and explicit knowledge and the need to encourage a knowledge-sharing environment, through informal interaction or socialization so that tacit knowledge does not leave with its carrier, if outsourcing occurs. The respondents in the study also emphasized that knowledge needs to be managed in a structured way, both with the help of IT tools but also to be included when conducting the manufacturing strategy, since it has a huge impact on both how (and if) an organization can 
produce and where to produce from. Another very important aspect is illustrated through the high degree of technology use. However, it is too early to understand the wider impact of what advancement in manufacturing technologies represents or how it will develop. Nevertheless, what we can see is that it will radically redefine the competitive landscape within many industries worldwide, since advanced technologies will enable organizations to bring back manufacturing activities to high cost locations.

Though, one of the key insights of this study shows that knowledge reintegration work might be equally important for a successful backsourcing strategy, implying that heavy investments in robotics and automation alone, is not enough. On the limitation side it should be mentioned that the study only represents one side of the table when terminating outsourcing contracts or relationships, missing potential barriers that might hinder the knowledge re-integration process or enablers smoothening the process. The small sample of interviews which might restrict the validity of the findings should also be mentioned.

\section{References}

1. Nujen, B.B., Halse, L.L., Solli-Sæther, H.: Backsourcing and Knowledge Reintegration: A Case Study. In: International Conference on Advances in Production Management Systems. pp. 191-198. Springer (2015)

2. March, J.G.: Exploration and Exploitation in Organizational Learning. Organization Science 2(1), 71-87 (1991)

3. Nonaka, I., Takeuchi, H.: The Knowledge-creating Company: How Japanese Companies Create the Dynamics of Innovation. Oxford University Press (1995)

4. Henriksen, B., Onsøyen, L.E.: Measuring the Intangible Aspects of the Manufacturing Strategy-A Case Study from the Automotive Industry. In: International Conference on Advances in Production Management Systems. pp. 383-391. Springer (2009)

5. Roos, G., Roos, G., Kennedy, N.: Manufacturing in a High Cost Environment-basis for Success on the Firm Level. Chapter 13, 393-480 (2014)

6. Mudambi, R.: Location, Control and Innovation in knowledge-intensive Industries. Journal of Economic Geography 8(5), 699-725 (2008)

7. Ellram, L.M., Tate, W.L., Petersen, K.J.: Offshoring and Reshoring. Journal of Supply Chain Management 49(2), 14-22 (2013)

8. Bals, L., Daum, A., Tate, W.: From Offshoring to Rightshoring: Focus on the Backshoring Phenomenon. AIB Insights 15(4), 3 (2015)

9. Bhagwatwar, A., Hackney, R., Desouza, K.C.: Considerations for Information Systems "backsourcing". Information Systems Management 28(2), 165-173 (2011)

10. Lacity, M.C., Willcocks, L.P., Rottman, J.W.: Global Outsourcing of Back Office Services. Strategic Outsourcing: An International Journal 1(1), 13-34 (2008)

11. Fratocchi, L., Di Mauro, C., Barbieri, P., Nassimbeni, G., Zanoni, A.: When Manufacturing Moves Back: Concepts and Questions. Journal of Purchasing and Supply Management 20(1), 54-59 (2014)

12. Polanyi, M.: The Tacit Dimension. Garden City, NY (1967)

13. Lam, A.: Tacit Knowledge, Organizational Learning and Societal Institutions: An Integrated Framework. Organization Studies 21(3), 487-513 (2000)

14. Grant, R.M.: Prospering in Dynamically-competitive Environments. Organization Science 7(4), 375-387 (1996) 